\title{
MAXIMUM LOAD CARRYING CAPACITY ESTIMATION OF THE SHIP AND OFFSHORE STRUCTURES BY PROGRESSIVE COLLAPSE APPROACH
}

\author{
Hasan Ölmez ${ }^{\mathrm{a}}$ \\ Ertekin Bayraktarkatal \\ a) Karadeniz Technical University, 61530, Trabzon, TURKEY \\ b) İstanbul Technical University, 34469, İstanbul, TURKEY
}

\begin{abstract}
The aim of the paper is to represent step by step progressive collapse analysis for maximum load carrying capacity estimation of a hull girder by using variant of Smith Method, named HULT by authors, with different element separation including single plates, stiffeners, hard corners and stiffened panels.

The structural elements that form the ships and offshore structures are exposed to large vertical bending moments and especially compression or tension forces in the longitudinal axis in case of hogging and sagging under bad sea conditions. In recent years, it becomes very important and valuable to practically, fast and nearly correct estimation of the maximum vertical bending moment just before breaks in two (collapse) under the worst conditions. The optimum (accuracy, time, practicality) estimation of these values depend on how accurate the stress-strain relation of the structural elements are established. In this first part of study, the ultimate strength behaviour of the stiffened panels in decks, bottoms and sides is estimated by developed semi-analytical method with updated orthotropic panel calculation approach under uniaxial (only longitudinal axis) compression loads. The second part of calculation is focused on the progressive collapse analysis of hull girders under longitudinal uniaxial compression with Smith Method but with different element discretization in contrast to the conventional beam-column elements. Also some benchmark studies of such methods on ultimate limit state assessment of stiffened panels and nine benchmark hull girders of ships are conducted, using some candidate methods such as IACS Common Structural Rules (CSR), FEA with Ansys v13 and HULT prepared by authors. The results from the tests, FEM analysis and different computational approaches are compared to determine performance of the method.
\end{abstract}

Keywords: Ship and offshore structure, stiffened panel, orthotropic panel, ultimate strength, progressive collapse analysis, Smith method.

\section{INTRODUCTION}

The ship and offshore structures' hulls consist of stiffened panels such as bottom construction, side shell construction, upper deck construction, watertight bulkheads. Unlike most land based structures, ships and offshore structures operate in a dynamic and unstable sea environment. The large number of loads caused by sea conditions and own cargos are much less than the structural capacity of the ship's hull girder. However, these structures must not only be designed according to be capable of withstanding normal loads, but also with extreme sea condition scenarios.

Two types of structural design methods are relevant for ship and offshore structures, namely "Allowable Stress Design" and "Limit State Design". Methodology used in this paper focused on Ultimate Limit State Design. This design is a philosophy in which the "capacity" (ultimate strength) of a structure is evaluated directly and compared to the "demand" (extreme load) applied to the structure [1]. Limit state design methods can be applied to a hull structure by applying longitudinal bending to the hull girder. Loads produce a distribution of longitudinal bending moments and compression/tension loads. If the bending moment value exceeds the ultimate strength value of the hull girder, the ship can fail due to buckling and progressive collapse of the compressed part [2]. At this point, the ultimate strength subject matter that shows us maximum load carrying capacity of hull girder under bending moment has been considered very important in the academic area and classification societies. Since the loads due to rough sea conditions, unusual loading and unloading of cargoes during operations acting on the ship hull are uncertain, the hull girder may collapse like breaking in two or something more catastrophic losses under these uncertain loads. 


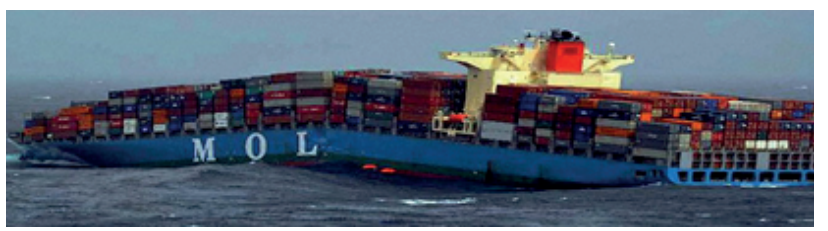

Fig. 1. MOL Comfort - 313 m length container ship broke in two in June 2013 [3]

Published researches about progressive collapse analysis of hull girder can be classified three categories such as: (1) derivation of theoretical methods to estimate progressive collapse or ultimate strength [2,4-12]; (2) results from theoretical modelling of sections using FEM approaches [13,14]; (3) reporting of physical experiments on box girders or ship structures [15].

One of the important methods to estimate the ultimate hull girder strength is idealized structural unit method (ISUM) developed by Ueda and Rashed [4]. For an ISUM type analysis the hull girder is usually divided into several different types of structural members such as support members (single stiffeners), beam-columns, rectangular plates and stiffened panels.

Another successful progressive collapse method is Smith Method [2]. This method is one of the simplified and most well recognized methods in the marine field to predict the global strength of a hull girder. In this paper, Smith Method principles are used for progressive collapse calculations of benchmark ship hull sections. This most useful hull girder ultimate strength evaluation method utilizes load-end shortening (stress-strain) curves describing the strength behaviour of structural elements including plates, stiffeners, stiffened plates and stiffened panels. For a progressive collapse type analysis the hull girder is usually discretized into plate-stiffener combination beam-column elements; each element comprises a single longitudinal stiffener with attached plating located between adjacent transverse frames. Failure of the hull girder in overall bending occurs by inter-frame failure of these elements.

According to the limit states based approach, the buckling collapse failure modes of a stiffened panel under compressive loads are: overall collapse after overall buckling of the plating and stiffeners as a unit, plate-induced failure by yielding at the corners of plating between stiffeners, plate-induced failure by yielding of stiffeners with attached plating at mid-span, stiffener induced failure by local buckling of stiffener web and stiffener-induced failure by lateral-torsional buckling or tripping of stiffeners [1]. It is known that the behaviour and collapse strength of stiffened panels under compressive loads depend on several factors as geometric and material properties, loading characteristics, boundary conditions and weldinginduced initial imperfections (initial distortions in the plate and residual stresses). For local elements, earlier works by many researchers have studied about tripping of stiffeners, stiffeners local buckling and ultimate strength of stiffened plates/panels under in-plane and lateral loads theoretically, experimentally and numerically [16-20]. Smith [19] presents a series of tests and FEM analysis on full scale welded steel grillages subjected to a combination of axial compression and lateral pressure. Paik et al. [20] extended the early works and provide an extensive contribution to the ultimate strength evaluations for stiffened panels by developing practical methods and empirical formulas. Benson et al. [8] investigated aluminium stiffened panels behaviours under uniaxial compressive loads and developed a semi-analytical method by using FEA and orthotropic plate theory. For more realistic analysis and results, all failure modes have to be considered [1]. In this study, according to our solution methodology all five modes are considered separately and collapse of stiffened panels occurs at the lowest value among the various ultimate loads. The semianalytical method described in this paper combines established empirical formulas of IACS-CSR [22] and large deflection orthotropic panel approach [20-21], for estimating the failure (buckling) modes of local single plate and stiffener elements, respectively with extended large deflection orthotropic method for estimating the global failure mode of stiffened panel [8].

\section{METHODOLOGY}

In this study, the steps presented below are followed respectively to obtain, firstly, the load-end shortening curve of discretized hull section elements and then the maximum load carrying capacity of hull girders.

At the beginning, the stiffener strength is evaluated using stress-strain curves derived from FEM analysis and IACSCSR equations describing the load-end shortening curve flexural-torsional (tripping) buckling and web local buckling of stiffeners (Step 1). Besides, the unstiffened plate strength is evaluated using standard stress-strain curves derived by using Marguerre [17] governing large deflection nonlinear equations of initially deflected single plate theory are extended from von Karman's [16] original equilibrium and compatibility equations (Step 2). Then, the plate-stiffener combination beam-column elements' strength is evaluated combining the plate and stiffener strength obtained from Step 1 and Step 2, respectively and a comparison is conducted with plate-stiffener combination buckling strength evaluation using standard stress-strain curves derived from IACS-CSR equations (Step 3). Then, the overall panel strength between two adjacent frames is evaluated by large deflection orthotropic panel approach but using renewed instantaneous longitudinal geometric properties like $\mathrm{E}_{\mathrm{x}}, \mathrm{D}_{\mathrm{x}}$ and etc. determined by instantaneous tangent modulus $\mathrm{E}_{\mathrm{T}, \mathrm{p}}$ and $\mathrm{E}_{\mathrm{t}, \mathrm{s}}$ from the plate components' and stiffener components' load shortening curves, respectively (Step 4). Peak load values obtained from load-end shortening curves of each step mentioned above are compared to determine the lesser one and the collapse strength of the stiffened panel (Step 5). Finally, progressive collapse calculations have been carried out for estimation of hull girder ultimate strength using loadend shortening curves obtained from previous steps (Step 6).

\section{DETERMINATION OF SINGLE STIFFENER COMPONENTS' STRESS-STRAIN RELATION BEHIND AND BEYOND THE ULTIMATE STRENGTH (STEP 1)}

Stiffeners' failure strength values can be determined by empirical formulas. In this paper, three different stress-strain curves such as single stiffener web buckling, single stiffener 
lateral torsional buckling and plate-stiffener combination beam-column buckling type failure behaviours are obtained by using IACS-CSR (2012), Appendix-A, Chapter 2.3. The results have been validated by non-linear FEM analysis with Ansys v13.

The peak load value of each curve is assumed as the ultimate strength for single stiffener. The curve that gives the minimum ultimate strength among three curves is used in extended orthotropic panel calculation process for Step 3 and Step 5 as $\mathrm{P}_{\text {stf }}$

\section{DETERMINATION OF SINGLE PLATE ELEMENT'S STRESS-STRAIN RELATION BEHIND AND BEYOND THE ULTIMATE STRENGTH (STEP 2)}

Large deflection plate theory used in this study allows examining the behaviour of initially deflected single rectangular plates under in-plane loads and lateral pressure. Foundations of the theory have been taken by von Karman to examine the behaviour of the initially flat plates. Marguerre, based on this equation, consider the plate with $\mathrm{z}=\mathrm{z}$ (x,y) form initial out of plane deflection. Summation of the out of plane deflection in mid-plate under loads $(w)$ and the initial out of plane deflection $(\mathrm{z})$ make the total plate out of plane deflection $(\mathrm{w}+\mathrm{z})$ at failure.

The governing nonlinear equations of large deflection plate theory extended by Marguerre from von Karman's original equilibrium and compatibility equations, respectively, obtained after algebraic manipulations for initially deflected single plates are as follows:

$\nabla^{4} \mathrm{~F}+\left\{\mathrm{E} \times \mathrm{t} \times\left[z_{, y y} \times \mathrm{w}_{, x x}+z_{, x x} \times \mathrm{w}_{, y y}-2 \times z_{, y x} \times \mathrm{w}_{, y x}-\mathrm{w}_{, y x}{ }^{2}+\mathrm{w}_{, y y} \times \mathrm{w}_{, x x}\right]\right\}=0$

$\left\{\mathrm{D} \times\left(\nabla^{4} \mathrm{w}\right)\right\}-\left\{\left[\mathrm{F}_{, x x} \times(z+w)_{y y}-2 \mathrm{~F}_{, y x} \times(z+w)_{y x}+\mathrm{F}_{, y y} \times(\mathrm{z}+\mathrm{w})_{, x x}\right]\right\}-\mathrm{Z}=0$

Here,

F: Airy stress function t: Plate thickness

D: Plate flexural rigidity

E: Young's modulus Z: Lateral load

Since the page restrictions, the details of the calculations can be seen in references $[10,18,21]$.

\section{MEMBRANE STRESS APPROACH (PLATE EDGE ORIENTED PLASTIC HINGE APPROACH)}

After buckling, the stresses move towards to plate edges due to membrane effects and can still resist against increasing loads until ultimate load carrying capacity. By considering initial distortions, the maximum membrane stress can occur either at the plate edges or at the tension region breadth. Minimum membrane stresses occur in the middle of the plate. When the membrane stresses of plate edges reach element material yield stress, no longer the in-plane displacements can be suppressed and plate collapse after large deflection due to increased large yielding region.
The membrane stresses, than, can be calculated by equations (3) and (4) obtained using the Airy stress function, load functions and determined deflection value $\left(\mathrm{w}_{0}\right)$ with assuming the unloaded edges kept straight.

$$
\sigma_{\mathrm{x}}=\frac{1}{\mathrm{t}} \times \frac{\partial^{2} \mathrm{~F}}{\partial \mathrm{y}^{2}}=\left(\sigma_{\mathrm{xav}}+\sigma_{\mathrm{r}}\right)+\left[\frac{\mathrm{E} \times \mathrm{w}_{0} \times\left(\mathrm{w}_{0}+2 \mathrm{z}_{0}\right) \cdot \times \mathrm{m}^{2} \times \cdot \beta^{2}}{8} \times \cdot \cos 2 \beta \mathrm{y}\right]
$$

$$
\sigma_{\mathrm{y}}=\frac{1}{\mathrm{t}} \times \frac{\partial^{2} \mathrm{~F}}{\partial \mathrm{x}^{2}}=-\frac{\mathrm{E} \times \mathrm{w}_{0} \times\left(\mathrm{w}_{0}+2 \mathrm{z}_{0}\right) \times \mathrm{m}^{2} \times \lambda^{2}}{8} \times \cos 2 \lambda \mathrm{x}
$$

Here;

$\sigma_{\text {xav }}:$ Averaged applied stress $\quad \beta: \pi / b \quad$ b: Plate width $\sigma_{\mathrm{r}}:$ Residual stress $\quad \lambda: \pi / \mathrm{L} \quad \mathrm{L}$ : Plate length $\mathrm{m}$ : Number of half-sine wave at buckling mode shape

According to the membrane stress distribution towards both the length and width of a single plate, there are three possible regions for beginning of plastic yielding: midpoint of unloaded edges, midpoint of loaded edges and each of four corner points [21]. In this approach, the three possible plasticities $\left(\sigma_{(\mathrm{vm}-1)}, \sigma_{(\mathrm{vm}-2)}\right.$, $\left.\sigma_{(\mathrm{vm}-3)}\right)$ is checked by von-Mises equivalent yield criterion of plate material. The load is increased step by step and it is assumed that the plate will collapse if the von-Mises equivalent yield criterion values reach the material yielding stress. The ultimate load caused this yielding stress is assumed as the ultimate collapse strength of plate.

$\sigma_{\mathrm{vm}-2}=\sqrt{\sigma_{\mathrm{xmin}}^{2}-\left(\sigma_{\mathrm{xmin}} \times \sigma_{\mathrm{ymax}}\right)+\sigma_{\mathrm{ymax}}{ }^{2}+3 \tau^{2}}=\sigma_{\mathrm{Y}}:$ loaded edge mid-width [21]

The details of the calculations including the maximum and minimum membrane stress equations with considering welding residual stresses and initial deflections can be seen in references $[10,20,21]$.

\section{DETERMINATION OF INTER-FRAME LOCAL PANEL STRENGTH (STEP 3)}

Plate and stiffener elements' resistances are estimated using the properties of the individual load shortening curves defined in the previous two steps. Two separate calculations are used to determine inter-frame local panel resistance at a given end shortening

1. The resistance of the plate and stiffener as defined by the individual load shortening curves are merged to determine a combination resistance, $\mathrm{P}_{\mathrm{p}-\mathrm{s}}$.

2. The combination resistance is then compared to the plate-stiffener combination buckling strength, $\mathrm{P}_{\mathrm{b}-\mathrm{c}}$ obtained using standard stress-strain curves derived from IACS-CSR equations.

The instantaneous beam-column element resistance (load value), $\mathrm{P}_{c}$ is the lesser of these two calculated values. These steps are repeated in an incremental analysis to produce a complete plate-stiffener load shortening curve. Beam-column collapse is indicated if $\mathrm{P}_{c}$ becomes less than $\mathrm{P}_{\text {plt }}$ or $\mathrm{P}_{\text {stf }}$. If $\mathrm{P}_{c}$ remains greater than $\mathrm{P}_{\text {plt }}$ or $\mathrm{P}_{\text {stf }}$, failure is assumed to be by stiffener tripping or local plate failure depending on which component load shortening curve peaks first. 


\section{COMBINATION STRENGTH OF CORRESPONDING LOCAL PLATE AND STIFFENER ELEMENTS STRENGTH}

Paik and Thayamballi (2003) gives a simple equation to estimate peak strength of a combined element $\left(\mathrm{P}_{\mathrm{p}-\mathrm{s}}\right)$ by combining the plate and stiffener strength using the proportional area of each component:

$$
P_{p-s}=\frac{\left[P_{p l t} \times b \times t\right]+\left[P_{s t f} \times\left(\left(h_{w} \times t_{w}\right)+\left(b_{f} \times t_{f}\right)\right)\right]}{(b \times t)+\left(h_{w} \times t_{w}\right)+\left(b_{f} \times t_{f}\right)}
$$

The combination strength includes plate buckling, stiffener web buckling and stiffener lateral torsional buckling, which are essentially local individual failures, but does not include beam column buckling where the plate and stiffener fail as one unit. Besides, this one unit buckling, $\mathrm{P}_{\mathrm{b}-\mathrm{c}}$ is evaluated by standard stress-strain curves derived from IACS-CSR equations [22].

\section{CALCULATION OF STIFFENED PANEL'S INSTANTANEOUS ULTIMATE STRENGTH WITH UPDATED LARGE DEFLECTION ORTHOTROPIC \\ PANEL APPROACH BY USING STRESS-STRAIN CURVES OBTAINED IN STEP 1 AND STEP 2 (STEP 4).}

As mentioned and emphasized earlier, the main resistant parts of ship and offshore structure hull girders are stiffened panels. The elastic overall panel buckling value can be determined using one formulae in classical orthotropic panel theory. Therefore, it is not possible to evaluate post-buckling and collapse behaviour. In this paper, more realistic stressstrain relation of stiffened panel behind and beyond the buckling is obtained using renewed large deflection orthotropic panel theory. This approach depends on element discretization such as single stiffeners and single plates. To derive the stiffened panel load-end shortening curve, solution process is conducted by using these components' stress-strain curves with iterative semi-analytical approach. In this method, the axial load is applied and controlled by increasing the axial endshortening iteratively. In each iterative step, all single element stresses are compared with overall panel stress derived by renewed orthotropic calculation. The minimum stress among them determines the stress-strain relation for that step. The important point here is, the instantaneous tangent modulus $\left(\mathrm{E}_{\mathrm{Tp}, \mathrm{i}}, \mathrm{E}_{\mathrm{Ts}, \mathrm{i}}\right)$, updated at each step, of each single elements' stressstrain curves are used to re-calculate the elastic constants $\mathrm{E}_{x}$ and $\mathrm{E}_{\mathrm{y}}$ at that step for conducting orthotropic panel solution [8]. In post-collapse region, the stress-strain relation is evaluated similar to the single plates but using overall elastic buckling $\left(\sigma_{(x E, O)}\right)$ of stiffened panel instead of elastic buckling of single plate.

\footnotetext{
APPLICATION OF INCREMENTAL ITERATIVE APPROACH TO THE STIFFENED PANEL FOR DETERMINATION OF THE STIFFENED PANEL'S STRESSSTRAIN RELATION BEHIND AND BEYOND THE ULTIMATE STRENGTH (STEP 5)
}

The results of four steps mentioned above are used for calculations in this step. Description of the procedure to easy understanding is presented below and calculation flowchart is given in Fig. 2.

1 - The single stiffener strength $\left(\mathrm{P}_{\text {stf }}\right)$ and single plate strength $\left(\mathrm{P}_{\mathrm{plt}}\right)$ are evaluated from curve obtained in Step 1 and Step 2, respectively.

2 - The corresponding local combined plate-stiffener element strength, $\mathrm{P}_{\mathrm{p}-\mathrm{s}}$, is calculated by combining $\mathrm{P}_{\text {stf }}$ and $\mathrm{P}_{\mathrm{plt}}$.

3 - The plate-stiffener combination beam-column element strength, $\mathrm{P}_{\mathrm{b}-\mathrm{c}}$, is evaluated from stress-strain curves derived from IACS-CSR equations.

4 - The inter-frame local panel strength, $\mathrm{P}_{c}$ is the minimum of $\mathrm{P}_{\mathrm{p}-\mathrm{s}}$ and $\mathrm{P}_{\mathrm{b}-\mathrm{c}}$.

5 - The instantaneous overall orthotropic panel strength, $\mathrm{P}_{\mathrm{o}-\mathrm{p}}$, is obtained using updated orthotropic panel calculations for stiffened panels.

6 - The instantaneous panel strength value, $P_{\text {pnl }}$, is chosen to be the minimum of $\mathrm{P}_{c}$ and $\mathrm{P}_{\mathrm{o}-\mathrm{p}}$. At each axial displacement increment, $\mathrm{P}_{\text {pnl }}$ provides an additional point for the panel loadend shortening curve.

7 - Similar calculations 1 to 6 is repeated until ultimate strength is reached, then a simpler post collapse curve can be postulated by taking the initial gradient from the post collapse point and assuming a linear post collapse curve [8].

\section{PROGRESSIVE COLLAPSE CALCULATIONS OF HULL GIRDER ULTIMATE STRENGTH (STEP 6)}

The main considered methodology employed in this part is the Smith method [4]. This method is the best established, simplified and the most appropriate method for progressive collapse analysis. The moment-curvature relationship is calculated by forcing an incremental curvature around the actual neutral axis of the hull section. Details of method can be seen in published papers and books $[1,2,8,9,10,21]$. The considered method presented in this study is composed from ISUM based element discretization and Smith based iterative collapse analysis including orthotropic panel calculations for stiffened panels updated in every load step. Within the method, stiffened panel elements' load-end shortening (stress-strain) relations behind and beyond the ultimate strength are obtained by updated orthotropic panel calculation procedure but using stress-strain curves of several type single stiffeners and single plates. The sample of calculation table and calculation flowchart can be seen in Table 1 and Figure 3, respectively. Details of this procedure and obtaining the load-end shortening curves of other single elements can be find in studies of Benson [8] and Olmez [10].

Table 1. Progressive collapse analysis calculation table

\begin{tabular}{|c|c|c|c|c|c|c|}
\cline { 2 - 7 } \multicolumn{1}{c|}{} & \multicolumn{1}{c|}{ Instantaneous Curvature } & $\kappa_{\mathrm{i}}$ & \multicolumn{2}{|c|}{ Instantaneous Neutral Axis Position } & $\mathrm{z}_{\mathrm{Ti}}$ \\
\hline El. No & $\mathrm{z}_{\mathrm{ij}}$ & $\Delta \mathrm{z}_{\mathrm{ij}}$ & $\varepsilon_{\mathrm{ij}}$ & $\mathrm{du}_{\mathrm{ij}}$ & $\mathrm{P}_{\mathrm{ij}}$ & $\mathrm{M}_{\mathrm{ij}}$ \\
\hline $\mathrm{j}: 1,2,3$ & $\mathrm{z}_{\mathrm{ij}}$ & $\mathrm{z}_{\mathrm{ij}}-\mathrm{z}_{\mathrm{Ti}}$ & $\varepsilon_{\mathrm{ij}}=\mathrm{\kappa}_{\mathrm{i}} \times \Delta \mathrm{z}_{\mathrm{ij}}$ & $\varepsilon_{\mathrm{ij}} \times \mathrm{L}$ & From P-du curves & $\mathrm{P}_{\mathrm{ij}} \times \Delta \mathrm{z}_{\mathrm{ij}}$ \\
\hline $\mathrm{i}:$ iteration number $; \mathrm{j}$ : element number & \multicolumn{1}{l}{} & $\Sigma \mathrm{P}_{\mathrm{i}}=0$ & $\Sigma \mathrm{M}_{\mathrm{i}}$ \\
\hline
\end{tabular}




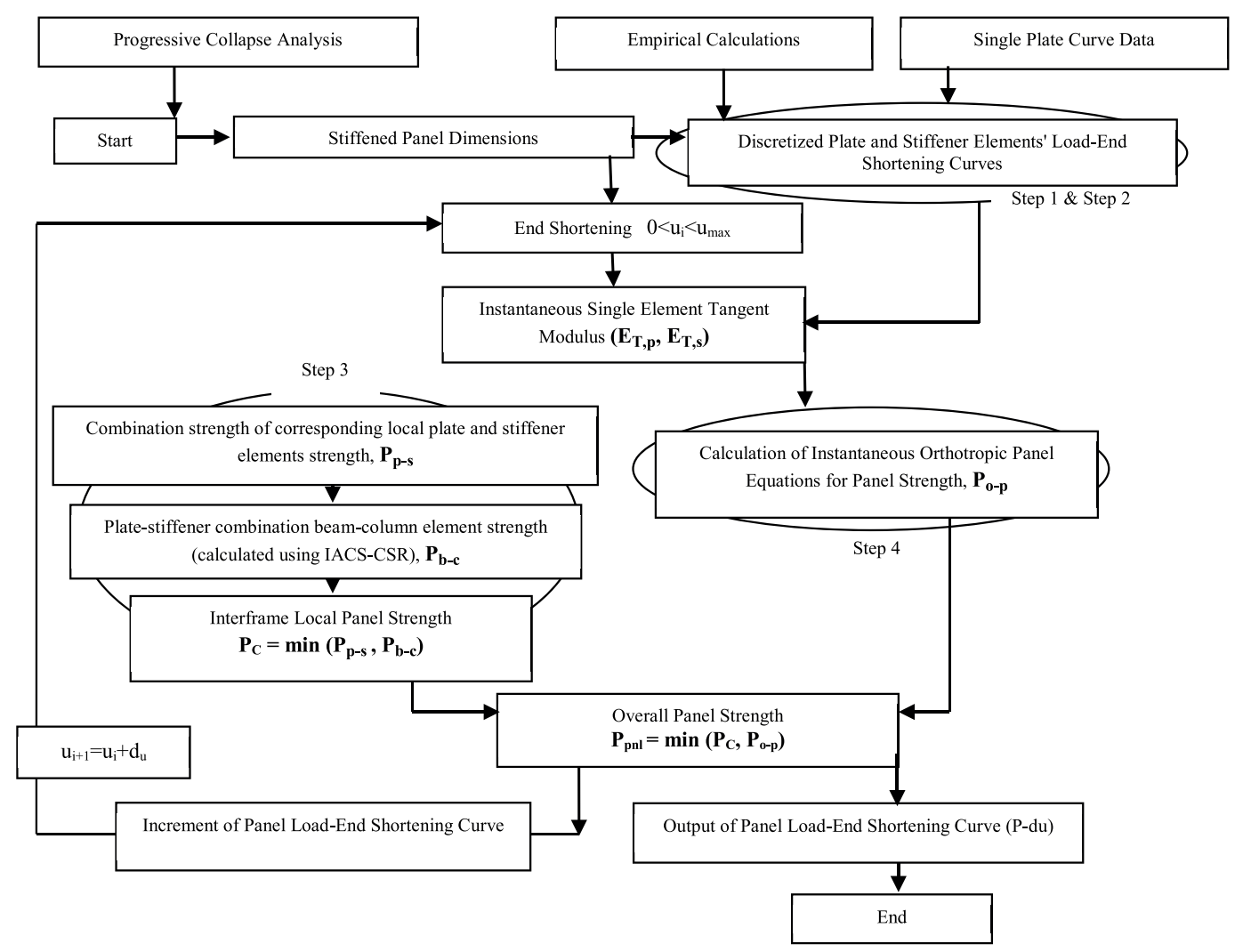

Fig. 2. Stiffened panel load-end shortening curve derivation flow chart

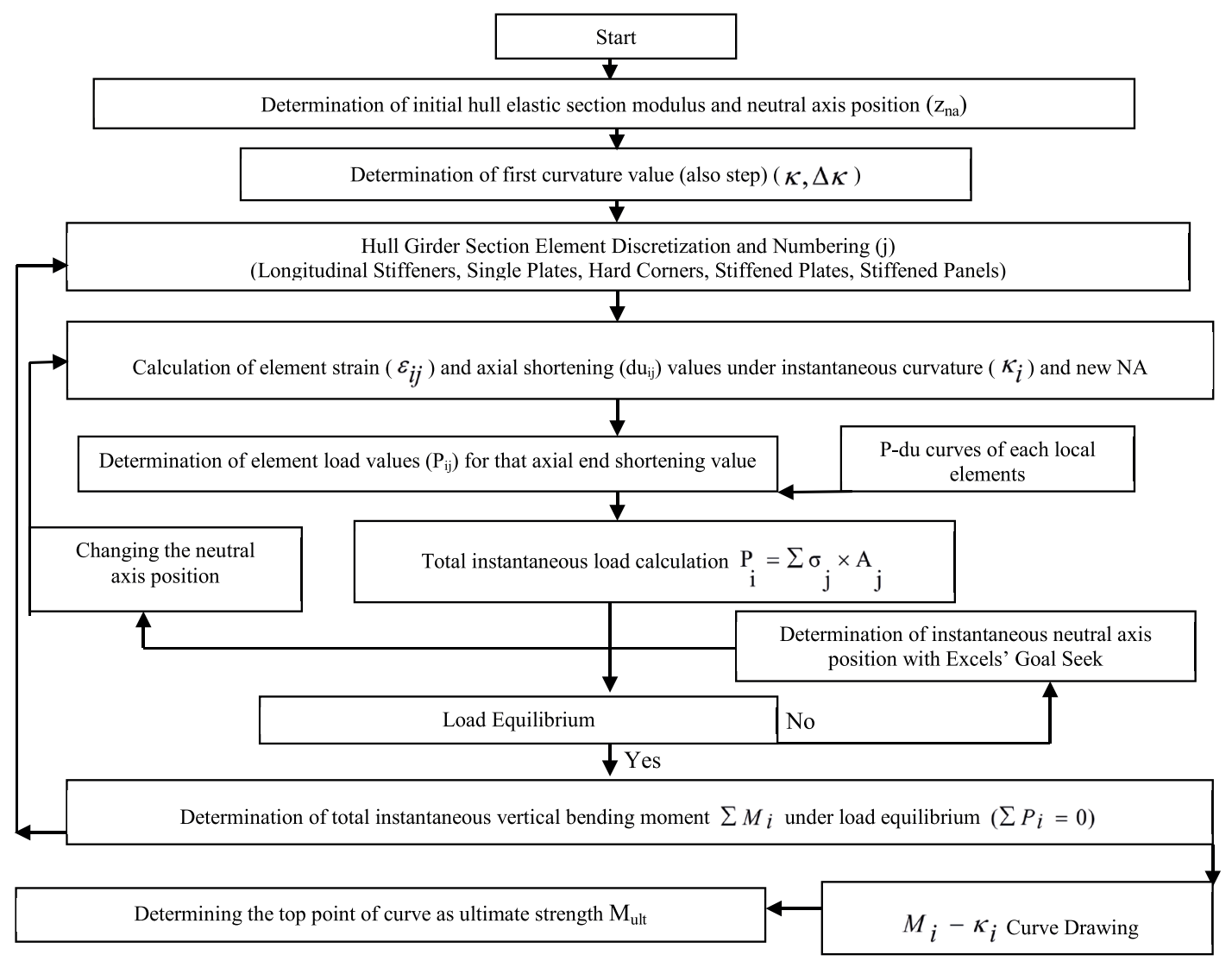

Fig. 3. Progressive collapse calculation flowchart used in presented study 


\section{CONSIDERED SHIPS OF VALIDATION BENCHMARK STUDY}

The accuracy of strength predictions of ship hull girders is now examined in order to validating HULT's ultimate strength procedures for ship and offshore structures. This is accomplished through evaluations of nine benchmark case studies for which detailed structural information and associated numerical or measured results have been reported in references $[11,23,24]$.

\section{CROSS SECTIONS AND STRUCTURAL CHARACTERISTICS}

In this part, the characteristics of progressive collapse behaviour of merchant ships under vertical sagging or hogging are investigated using the HULT code. The ten typical ship type designs represented with cross sections and main hull section properties have been studied. The cross sections of ten ships and main hull section properties are shown in Fig.4 and Table 2, respectively.

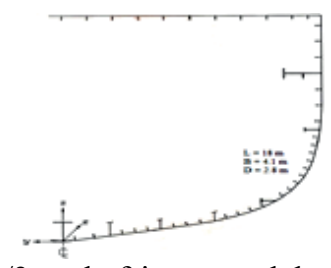

$1 / 3$ scale frigate model - FRG

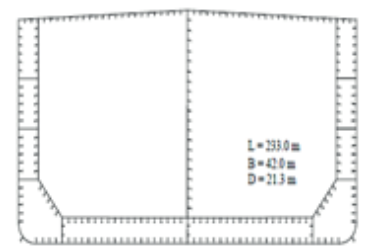

Double Hull Oil Tanker - DHOT1

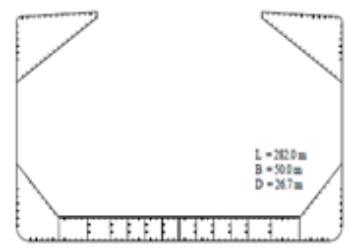

Single Sided Bulk Carrier - SSBC

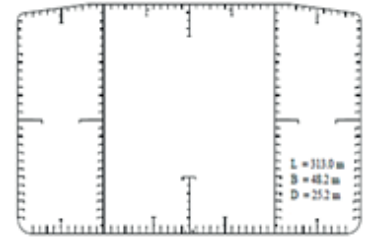

Single Hull VLCC Oil Tanker -SHOT

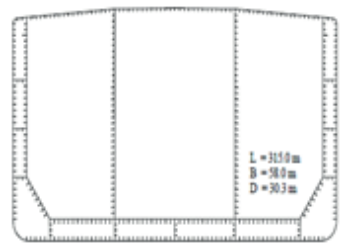

Double Hull Oil Tanker - DHOT2

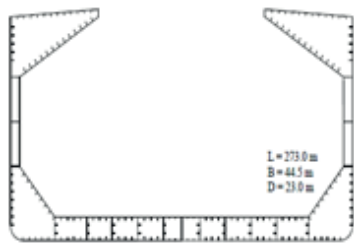

Double Sided Bulk Carrier - DSBC

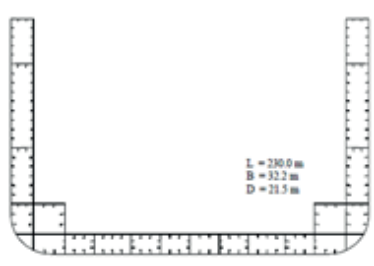

3.500 TEU Container - CNT35

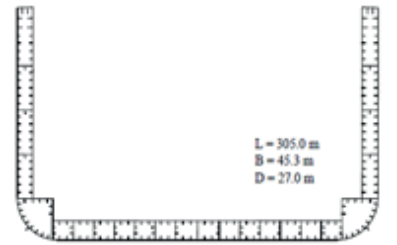

9.000 TEU Container - CNT90

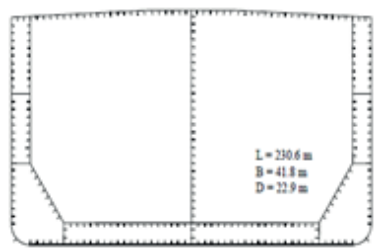

113.000 DWT FPSO - FPSO

Fig. 4. Mid-ship cross sections of nine benchmark case ships

Table 2. Principal dimensions of the nine typical ship hull sections.

\begin{tabular}{|c|c|c|c|c|c|c|c|c|c|c|c|}
\hline \multicolumn{2}{|c|}{ Hull Sec. Prop. } & FRG & SHOT & CNT35 & DHOT1 & DHOT2 & SSBC & DSBC & CNT90 & FPSO & DHOT3 \\
\hline \multicolumn{2}{|c|}{ Length (m) } & 18 & 313 & 230 & 233 & 315 & 282 & 273 & 305 & 230.6 & 182.5 \\
\hline \multicolumn{2}{|c|}{ Breadth (m) } & 4.2 & 48.2 & 32.2 & 42 & 58 & 50 & 44.5 & 45.3 & 41.8 & 32.2 \\
\hline \multicolumn{2}{|c|}{ Depth (m) } & 2.8 & 25.2 & 21.5 & 21.3 & 30.3 & 26.7 & 23 & 27 & 22.9 & 18.1 \\
\hline \multicolumn{2}{|c|}{ Draft (m) } & - & 19 & 12.5 & 12.2 & 22 & 19.3 & 15 & 13.5 & 14.15 & 12.6 \\
\hline \multicolumn{2}{|l|}{$\mathrm{Cb}$} & - & 0.83 & 0.68 & 0.83 & 0.82 & 0.83 & 0.84 & 0.65 & 0.83 & 0.77 \\
\hline \multicolumn{2}{|c|}{ Sec. Area $\left(\mathrm{m}^{2}\right)$} & - & 7.858 & 3.84 & 5.31 & 9.64 & 5.65 & 5.79 & 6.19 & 4.88 & 3.03 \\
\hline \multicolumn{2}{|c|}{ N. Axis (m) } & 1.42 & 12.10 & 8.50 & 9.19 & 12.97 & 11.19 & 10.06 & 11.61 & 10.22 & 7.68 \\
\hline \multicolumn{2}{|c|}{ I (Vertical) $\left(\mathrm{m}^{4}\right)$} & 0.06 & 863.7 & 237.5 & 359.5 & 1346.1 & 694.3 & 508.3 & 682.8 & 393.6 & 164.8 \\
\hline \multirow{2}{*}{$\begin{array}{c}\mathrm{z} \\
\left(\mathrm{m}^{3}\right)\end{array}$} & Deck & 0.03 & 66.30 & 18.33 & 29.68 & 77.23 & 44.35 & 39.27 & 44.38 & 31.04 & 13.81 \\
\hline & Bottom & 0.04 & 70.95 & 27.23 & 39.13 & 103.77 & 62.06 & 50.54 & 58.79 & 38.52 & 18.72 \\
\hline \multirow{2}{*}{$\begin{array}{c}\sigma_{\mathrm{y}} \\
(\mathrm{MPa})\end{array}$} & Deck & 245 & 315 & 355 & 315 & 315 & 390 & 355 & 355 & 315 & 245 \\
\hline & Bottom & 245 & 315 & 315 & 315 & 315 & 315 & 315 & 315 & 315 & 315 \\
\hline
\end{tabular}

Neutral Axis: Ship hull cross section neutral axis identifies a plane along which there is neither tension nor compression. I (vertical): Moment of inertia of cross-sectional area about neutral axis.

z: Ship hull girder section modulus. 


\section{PROGRESSIVE HULL COLLAPSE ANALYSIS AND CALCULATED RESULTS}

The ultimate vertical bending moment of the ten hull structures are studied using HULT and IACS-CSR (KTU) [10, 22], then the results are compared with published results $[5,7,8,9,10,11,12,23,24]$. It is noted that the hull structural dimensions applied for the all analysis were defined by including $50 \%$ corrosion margin $\left(0.5 \times \mathrm{t}_{\text {corr }}\right)$ values of individual structural components as specified by IACS-2006a causes obtained results as incomparable with all other results. Fig. 5 shows IACS-CSR and HULT models employed for the progressive hull collapse analysis under vertical bending. Hull cross-section model between two adjacent transverse frames at mid-ship is adopted as the extent of the analysis. For HULT code modelling, structural elements between support members are idealized such as single stiffeners, single plates, single stiffeners with attached plating, hard corners and identically stiffened panels.

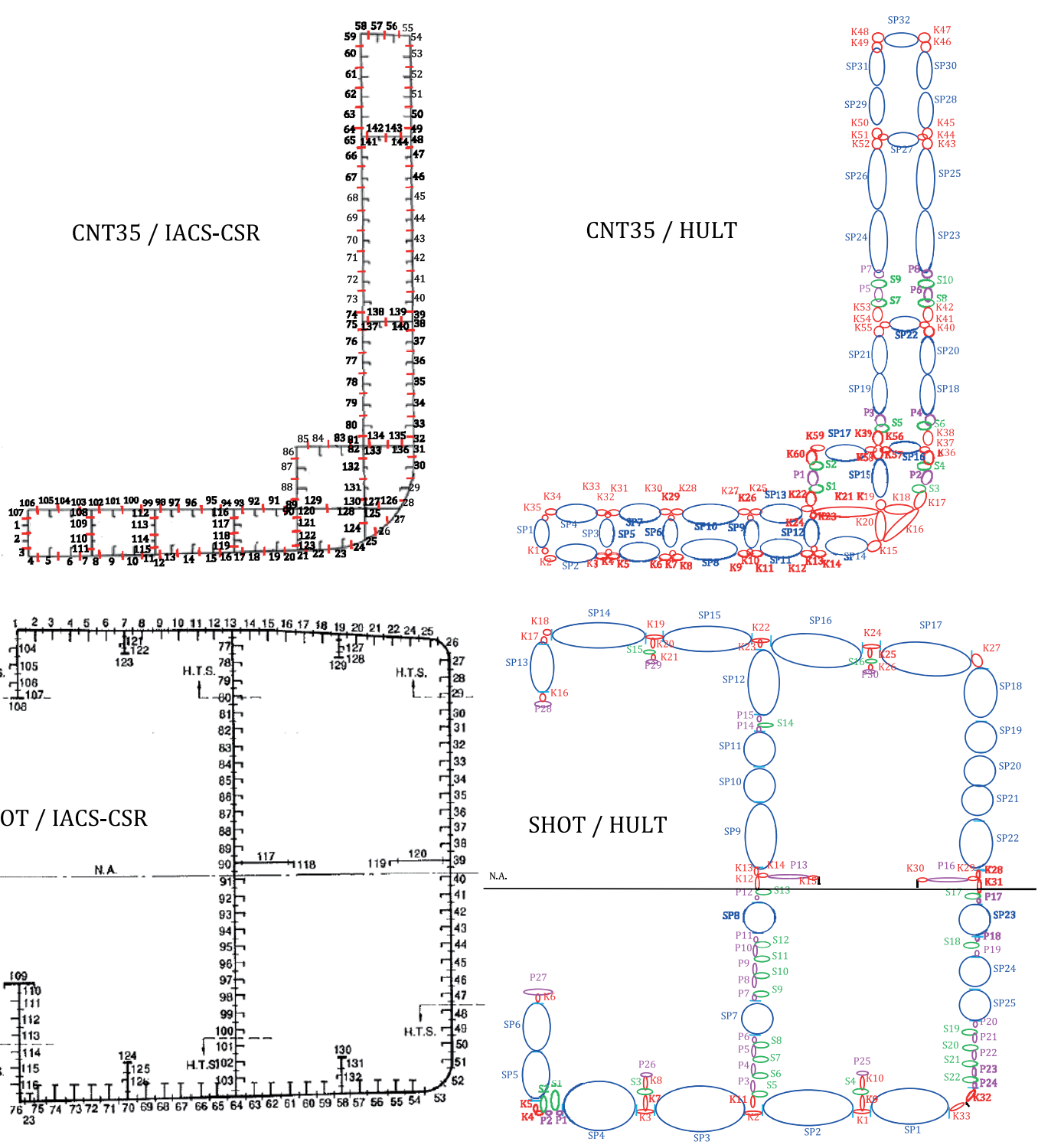

Fig. 5. Element discretization of CNT35 and SHOT with HULT and IACS-CSR

The main assumptions used for ten hull girder progressive collapse calculations are:

1 - Analysis are carried out between two transverse frames.

2 - Plane sections remain plane after bending (Euler-Bernoulli Bending Theory).

3 - The neutral axis of the hull cross section changed as the collapse of individual structural components progressively occurs. Decrease or increase of the neutral axis position according to hogging or sagging is taken into account as the vertical bending moment is increasingly applied.

4 - Average level welding residual stresses $\left(0.15 \times \sigma_{0}\right)$ is considered [21]. 
5 - Buckling mode average level initial deflection $\left(0.1 \times \beta^{2} \times \mathrm{t}\right)$ is considered [21].The result comparison of hogging and sagging condition ultimate strength calculations with HULT, IACS-CSR and published other results obtained by different authors using various methods are comparatively represented in Table 3 and Fig. 6, respectively.

Table 3. Summary of benchmark ship's ultimate bending moments for all methods

\begin{tabular}{|c|c|c|c|c|c|c|c|c|c|c|c|}
\hline & \multirow{2}{*}{ Remarks } & \multicolumn{2}{|c|}{ FRG } & \multicolumn{2}{|c|}{ SHOT } & \multicolumn{2}{|c|}{ CNT35 } & \multicolumn{2}{|c|}{ DHOT1 } & \multicolumn{2}{|c|}{ DHOT2 } \\
\hline & & Hog. & Sag. & Hog. & Sag. & Hog. & Sag. & Hog. & Sag. & Hog. & Sag. \\
\hline \multirow{28}{*}{ 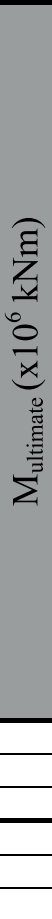 } & 1. Chen*[46] & 12.49 & 9.54 & 20.23 & 18.54 & 6.56 & 5.47 & - & - & 27.40 & 24.33 \\
\hline & 2. Cho*[46] & 11.32 & 9.48 & 20.09 & 16.75 & 6.69 & 5.13 & - & - & 28.66 & 20.80 \\
\hline & 3. $\quad$ Masaoka*[46] & 12.49 & 11.50 & 20.01 & 19.00 & 8.07 & 7.95 & - & - & 30.59 & 26.59 \\
\hline & 4. $\operatorname{Rigo}(1) *[46]$ & 13.26 & 9.47 & 18.46 & 17.90 & 7.60 & 6.51 & - & - & 28.32 & 19.57 \\
\hline & 5. $\quad \operatorname{Rigo}(2) *[46]$ & 12.12 & 9.88 & 17.54 & 17.10 & 7.20 & 6.91 & - & - & 25.61 & 24.07 \\
\hline & 6. $\quad Y a o *[46]$ & 10.90 & 8.58 & 19.03 & 16.84 & 6.72 & 6.72 & - & - & 28.88 & 20.42 \\
\hline & 7. $\quad$ ALPS/HULL[19] & 10.45 & 9.94 & 16.77 & 15.83 & 6.92 & 6.64 & 8.49 & 6.90 & 23.59 & 19.57 \\
\hline & 8. $\quad$ Paik-FEM [47] & - & 9.62 & 17.36 & 16.18 & 6.97 & 6.95 & - & - & 27.34 & 22.50 \\
\hline & 9. $\quad$ Mod.P-M [47] & - & - & 18.70 & 17.83 & 6.4 & 7.08 & - & - & 25.67 & 22.39 \\
\hline & 10. Benson $*[25]$ & - & 10.20 & - & - & - & - & - & - & - & - \\
\hline & 11. ISR-FEM [47] & - & - & 21.2 & 20.2 & 7.49 & 7.18 & - & - & 30.11 & 28.18 \\
\hline & 12. CR-FEM [47] & - & - & 21.86 & 20.63 & 7.66 & 7.63 & - & - & 31.00 & 25.00 \\
\hline & 13. Ozguc*[23] & 12.01 & 9.60 & 17.89 & 16.45 & 6.79 & 6.70 & - & - & 27.45 & 21.15 \\
\hline & 14. Tayyar* $[24]$ & - & 9.74 & 17.02 & - & - & - & - & - & - & - \\
\hline & 15. Dow $[10]$ & 11.39 & 9.64 & 18.80 & - & - & - & - & - & - & - \\
\hline & 16. Ruth.\&Caldwell & - & - & 17.94 & - & - & - & - & - & - & - \\
\hline & 17. $C S R-C R *[47]$ & - & - & 20.71 & 18.59 & 7.88 & 7.59 & & & 29.85 & 25.01 \\
\hline & 18. CSR-PNU *[47] & - & - & 20.10 & 18.71 & 7.76 & 6.85 & & & 28.42 & 22.13 \\
\hline & 19. Rina Rules* [47] & - & - & 19.84 & 18.47 & 6.86 & 5.90 & & & 28.20 & 21.67 \\
\hline & 20. $C S R-F S B *[20]$ & - & - & 19.41 & 18.30 & 7.58 & 6.82 & & & 28.43 & 21.16 \\
\hline & 21. CSR-KTU* [26] & 12.11 & 10.25 & 19.30 & 18.03 & 7.25 & 6.65 & 8.75 & 6.95 & 28.11 & 20.58 \\
\hline & 22. $H_{U L T}^{*}$ & 12.18 & 9.53 & 17.66 & 16.95 & 7.34 & 6.68 & 8.61 & 7.08 & 24.59 & 21.55 \\
\hline & Mean / All Methods & 11.86 & 9.784 & 19.04 & 17.91 & 7.21 & 6.74 & 8.62 & 6.98 & 28.01 & 22.62 \\
\hline & St.Dv. / All Methods & 0.841 & 0.633 & 1.416 & 1.314 & 0.492 & 0.702 & 0.13 & 0.09 & 1.798 & 2.426 \\
\hline & COV / All Methods & 0.071 & 0.065 & 0.074 & 0.073 & 0.068 & 0.104 & 0.013 & 0.018 & 0.064 & 0.107 \\
\hline & Mean/Smith Based & 12.09 & 9.80 & 19.09 & 17.82 & 7.25 & 6.61 & 8.68 & 7.02 & 28.04 & 22.08 \\
\hline & St.Dv./Smith Based & 0.728 & 0.857 & 1.179 & 0.878 & 0.500 & 0.763 & 0.092 & 0.091 & 1.577 & 2.221 \\
\hline & COV/Smith Based & 0.060 & 0.087 & 0.062 & 0.049 & 0.069 & 0.115 & 0.014 & 0.013 & 0.056 & 0.101 \\
\hline
\end{tabular}

Table 3 Cont. Summary of benchmark ship's ultimate bending moments for all methods

\begin{tabular}{|c|c|c|c|c|c|c|c|c|c|}
\hline & \multirow{2}{*}{ Remarks } & \multicolumn{2}{|c|}{ SSBC } & \multicolumn{2}{|c|}{ DSBC } & \multicolumn{2}{|c|}{ CNT90 } & \multicolumn{2}{|c|}{ FPSO } \\
\hline & & Hog. & Sag. & Hog. & Sag. & Hog. & Sag. & Hog. & Sag. \\
\hline \multirow{28}{*}{ 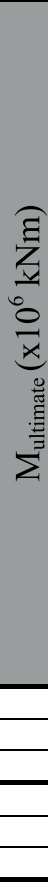 } & 1. Chen* [46] & 19.06 & 15.20 & - & - & - & - & - & - \\
\hline & 2. Cho* [46] & 18.99 & 13.69 & - & - & - & - & - & - \\
\hline & 3. Masaoka*[46] & 18.56 & 16.02 & - & - & - & - & - & - \\
\hline & 4. $\operatorname{Rigo}(1) *[46]$ & 18.71 & 14.34 & - & - & - & - & - & - \\
\hline & 5. $\operatorname{Rigo}(2) *[46]$ & 17.06 & 14.34 & - & - & - & - & - & - \\
\hline & 6. $\mathrm{Yao}^{2}[46]$ & 17.36 & 14.45 & - & - & - & - & - & - \\
\hline & 7. ALPS/HULL[19] & 16.60 & 15.38 & 12.03 & 12.2 & 13.08 & 16.60 & 8.76 & 7.28 \\
\hline & 8. Paik-FEM [47] & 17.50 & 15.80 & - & - & - & - & - & - \\
\hline & 9. Mod.P-M [47] & 16.58 & 14.8 & - & - & - & - & - & - \\
\hline & 10. Benson* $[25]$ & - & - & - & - & - & - & - & - \\
\hline & 11. ISR-FEM [47] & 18.33 & 17.73 & - & - & - & - & - & - \\
\hline & 12. CR-FEM [47] & 18.40 & 16.86 & - & - & - & - & - & - \\
\hline & 13. Ozguc* [23] & 17.34 & 14.19 & - & - & - & - & - & - \\
\hline & \begin{tabular}{|l|} 
14. Tayyar* [24] \\
\end{tabular} & - & - & - & - & - & - & - & - \\
\hline & 15. Dow [10] & - & - & - & - & - & - & - & - \\
\hline & 16. Ruth.\&Caldwell & - & - & - & - & - & - & - & - \\
\hline & 17. $C S R-C R *[47]$ & 18.34 & 14.92 & - & - & - & - & - & - \\
\hline & 18. CSR-PNU *[47] & 18.36 & 14.50 & - & - & - & - & - & - \\
\hline & \begin{tabular}{|l|} 
19. Rina Rules $*[47]$ \\
\end{tabular} & 17.48 & 13.95 & - & - & - & - & - & - \\
\hline & 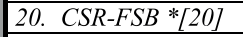 & 17.87 & 14.19 & - & - & - & - & - & - \\
\hline & 21. $C S R-K T U *[26]$ & 18.05 & 14.65 & 12.28 & 12.88 & 14.35 & 16.18 & 9.55 & 7.74 \\
\hline & 22. $H_{U L T}^{*}$ & 17.45 & 15.12 & 11.76 & 12.69 & 13.88 & 16.74 & 9.30 & 7.46 \\
\hline & Mean / All Methods & 17.89 & 15.01 & 12.02 & 12.25 & 13.77 & 16.51 & 9.202 & 7.491 \\
\hline & St.Dv. / All Methods & 0.758 & 1.044 & 0.260 & 0.410 & 0.642 & 0.291 & 0.402 & 0.234 \\
\hline & COV/All Methods & 0.042 & 0.069 & 0.022 & 0.034 & 0.047 & 0.018 & 0.041 & 0.032 \\
\hline & Mean / Smith Based & 18.05 & 14.58 & 12.02 & 12.29 & 14.12 & 16.46 & 9.43 & 7.60 \\
\hline & St.Dv./Smith Based & 0.674 & 0.612 & 0.368 & 0.573 & 0.332 & 0.397 & 0.176 & 0.19 \\
\hline & COV/Smith Based & 0.037 & 0.042 & 0.031 & 0.047 & 0.024 & 0.020 & 0.018 & 0.019 \\
\hline
\end{tabular}


Results obtained by methods 1 to $6,10,14,15$ and 18 to 22 were considered for calculation of Mean, St. Dv. and COV values of Smith Based (different formulations for obtaining the load-end shortening curves) calculations. Coefficient of variation (COV) calculated for all methods and Smith based methods are given in Table 3. COV for all methods varies from 0,013 to 0,107 and COV for Smith based methods varies from 0,013 to 0,115. Average COV calculated for considered groups are 0,053 and 0,049 , respectively. This decreasing on average COV shows that similarity of methods increases as expected. It can also be noted that closed results are obtained by various Smith based methods (1 to 6, 10, 14, 15, 20 and 22) and the IACS-CSR method implementations use same formulations for load-end shortening curves (18, 19, 21 and 22). Although standard formulations for standard element idealizations are used, there are small differences among CSR results due to researcher factors (code algorithm, structural discretization, assumptions, etc.).
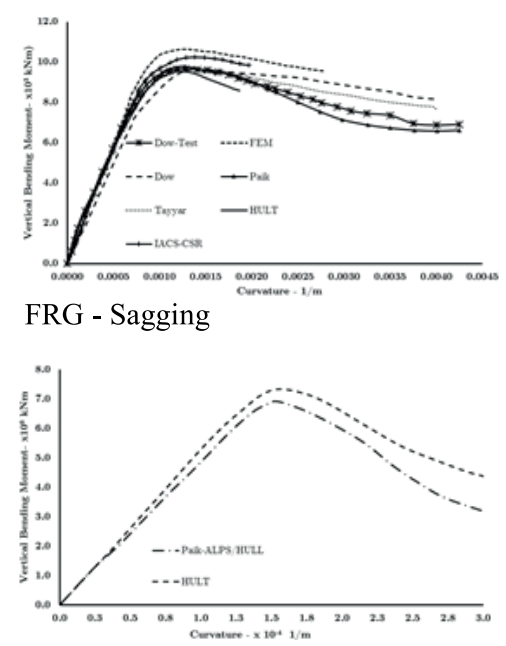

CNT35 - Hogging

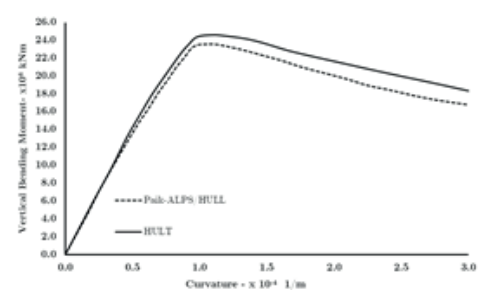

DHOT2 - Hogging

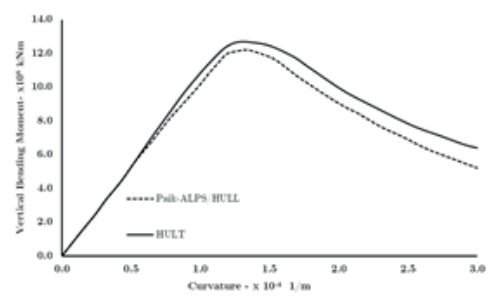

DSBC - Sagging
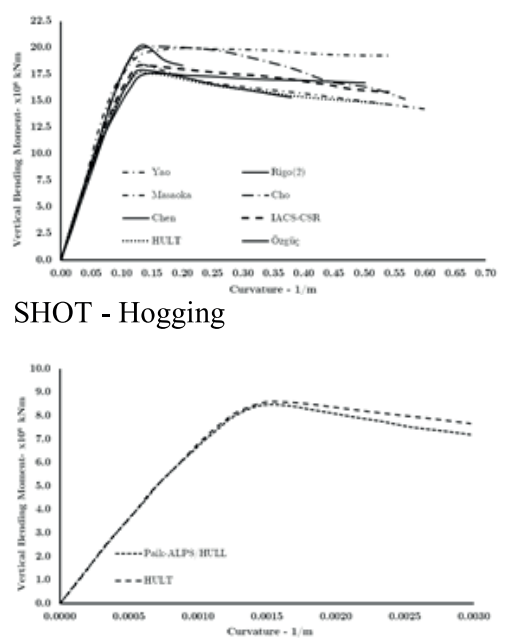

DHOT1 - Hogging

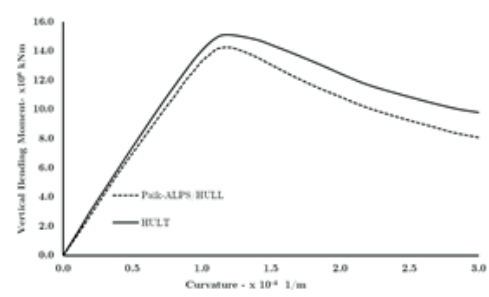

SSBC - Sagging

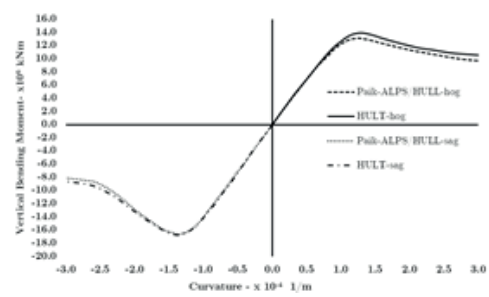

CNT90 - Sagging / Hogging

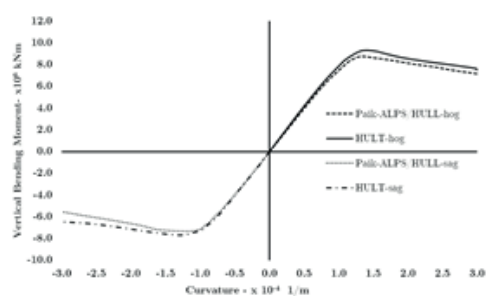

FPSO - Sagging / Hogging

Fig. 6. Moment-curvature curves of benchmark models 
If we zoom in one another moment-curvature curve of benchmark case ships, for example DHOT3 given in Table 2, we can clearly see and discuss which element(s) in which part of the hull section will collapse when. This is the main advantage of progressive collapse calculation approach. After progressive collapse analysis of DHOT3, it can be seen also in Fig. 7, the main deck longitudinals and the center line bulkhead upper longitudinals are collapsed firstly. After these elements, inner bulkhead upper longitudinals and side upper longitudinals are collapse. Finally, the side longitudinal elements around half the height of cross section are collapsed. Collapsed structural elements on the moment-curvature curve are presented in Fig. 7.

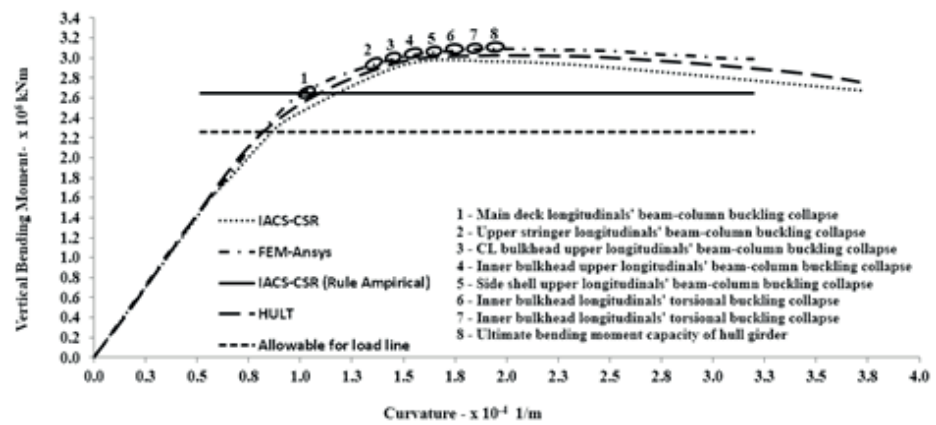

Fig. 7. Collapse sequence on moment-curvature curves of DHOT3 obtained by HULT

\section{CONCLUSION}

In this paper, first part (element stress-strain curve obtaining module) and second part (hull progressive collapse calculations) of the systematic calculation for hull girder ultimate strength analysis developed by authors, namely HULT is represented. The main target of the present study has been to bring out the reliability and applicability of stress-strain relations of stiffened panel elements to the hull girder collapse analysis and also bring out the reliability and applicability of progressive hull girder collapse calculations by HULT. Its reliability and applicability is tested by benchmark analysis for ten ships.

According to the results of verification case studies, as a main consequence, developed calculation flow including stressstrain curves for single plate, stiffener and stiffened panel can be reliably merged to progressive hull girder collapse analysis in terms of the resulting approximation. One of the other consequences should be highlighted is determination of the active role of orthogonal components' sizing and material stress-strain relation on the global failure of a stiffened panel. Considering these active effects, taking into consideration all possible types of failure provide a more realistic and more understandable calculation of stiffened panel ultimate strength.

For all benchmark ships detailed analysis of collapse sequence for both hogging and sagging conditions are performed. As expected, obtained ultimate strength (maximum load carrying capacity) values are higher for hogging than sagging for all benchmark ships except DSBC and CNT90 models. The collapse of the compression flange of the tanker hulls takes place prior to the yielding of the tension flange as expected from usual ship hull girders. Thus, the ultimate hogging moment of the tanker hull is higher than the ultimate sagging moment as usual. It should also be emphasized for all models that decks which collapse first even for hogging case are the most critical and determinant portion of the hull girder transverse section. In contrast to the usual behaviour of ship hull girders, it is observed for CNT90 that because the deck panels are very squat with large plate thickness, they do not buckle and do not collapse firstly in sagging case under axial compressive loads.

Similarly, because the deck panels of DSBC are typically much sturdier than bottom panels, in contrast to the tanker hulls, the bottom plates of the DSBC hull yields prior to buckling collapse of the deck plates under sagging condition. Under hogging condition, however, buckling collapse of the bottom plates takes place prior to yielding of the deck plates due to same reason. This result is contrary to what is normally expected ultimate strength characteristics of usual ship hull girders since the ultimate sagging moment of DSBC is higher than the ultimate hogging moment. For all that, because bulk carriers have large deck openings, the section modulus at bottom is much larger than that at deck.

Last of all, according to the results of verification case studies, it can be observed that calculations with HULT and implementation of IACS-CSR method used by authors are closely compatible with overall mean values for all benchmark ship hull girder models. Also, developed calculation flow including stress-strain curves for single plate, stiffener and stiffened panel can be reliably merged to progressive hull girder collapse analysis in terms of the resulting approximation. It should be also underlined that there will be less elements in the calculation table due to the selected structural element idealization and discretization. In this way, fewer load-axial end shortening curves will be needed and this will decrease the computation time. Hereby, HULT has adequate reliability to estimate hull girder ultimate bending moment and determining the collapse sequence of structural elements.

\section{BIBLIOGRAPHY}

1. [1] Paik, J.K., Thayamballi, A.K. : Ultimate limit state design of steel-plated structures. Chichester, UK: John Wiley \& Sons Ltd; 2003. 
2. Smith, C.S. :. Influence of local compressive failure on ultimate longitudinal strength of a ship's hull. PRADSInternational Symposium on Practical Design in Ship Building, Tokyo-Japan, (1977), pp. 73-79.

3. URL-1:http://www.vesselfinder.com/news/1223UPDATE-MOL-Comfort-Sank, 2013.

4. Ueda, Y., Rashed, S.M.H. : ISUM (Idealized Structural Unit Method) Applied to Marine Structures. Transactions of JWRI, Vol. 20 (1991), No.1, pp.123-136.

5. Dow, R.S., 1991. Testing and Analysis of a 1/3 Scale Welded Steel Frigate Model, Proc. Int. Conf. on Advances in Marine Structures, ARE, 749-773.

6. Paik, J.K., Mansour, A. A. : Simple formulation for predicting the ultimate strength of ships. Journal of Marine Science Technology, Vol. 1 (1995), pp. 52-62.

7. Özgüç, Ö. : Hull girder ultimate strength and fracture toughness of damaged marine structures. PhD Thesis, Universities of Glasgow and Strathclyde, Glasgow, 2006.

8. Benson S. : Progressive collapse assessment of lightweight ship structures. PhD Thesis, Newcastle University, Newcastle, 2011.

9. Tayyar, G.T. : Determination of ultimate strength of the ship girder. PhD Thesis, İstanbul Technical University, İstanbul, 2011.

10. Olmez, H. : Ultimate strength estimation of ship hull girders by progressive collapse analysis approach. $\mathrm{PhD}$ Thesis, Karadeniz Technical University, Trabzon, 2014.

11. Paik, J.K., Wang, G., Kim, B.J., Thayamballi, A.K. : Ultimate limit state design of ship hulls. SNAME Transactions, Vol. 110 (2002), pp. 85-114.

12. Andric, J., Kitarovic, S., Bicak, M. : IACS incrementaliterative method in progressive collapse analysis of various hull girder structures. Brodogradnja/Shipbuildıng, Vol. 65 (2014), No. 1, pp. 65-78.

13. Kim, D.K., Park, D.H., Kim, H.B., Kim, B.J., Seo, J.K., Paik, J.K. : Lateral pressure effects on the progressive hull collapse behaviour of a Suezmax-class tanker under vertical bending moments. Ocean Engineering, Vol. 63 (2013), pp. 112-121.

14. Benson, S., Downes, J., Dow, R.S. : Compartment level progressive collapse analysis of lightweight ship structures. Marine Structures, Vol.31 (2013), pp.44-62.

15. Rutherford, S.E., Caldwell, J.B. : Ultimate strength of ships: a case study. Trans Soc. Nav. Archit. Mar Eng., Vol. 98 (1990), pp. 441-471.
16. von Karman, T., Sechler, E.E. ve Donnell, L.H. : Strength of thin plates in compression. ASME Trans, Vol. 54 (1932), pp. 553-557.

17. Marguerre, K.. : Zur theorie der gekrümmmter platte grosser formanderung Proc. 5th Int. Congress Appl. Mech., Vol. 93 (1938).

18. Murray, N.W., Introduction to the theory of thin-walled structures. Clarendon Press, Oxford, 1984.

19. Smith, C. S. : Compressive strength of welded steel ship grillages. Transactions of the Royal Institution of Naval Architects, Vol. 118 (1976), pp. 325-359.

20. Paik J.K., Thayamballi A.K., Kim B.J.: Large deflection orthotropic plate approach to develop ultimate strength equations for stiffened panels under combined biaxial compression/tension and lateral pressure. Thin-Wall Structures, Vol. 39 (2001), No.3,

pp. 215-246.

21. Hughes, O. and Paik, J. K. : Ship structural analysis and design. SNAME, New Jersey, 2010.

22. IACS, Common structural rules for double hull oil tankers. International Association of Classification Societies, 2012

23. Technical Committee VI.2 : Ultimate Hull Girder Strength. Proceedings of the 14th International Ship and Offshore Structures Congress, Vol.2 (2000), Nagasaki.

24. Technical Committee III.1. Ultimate strength, Proceedings of the 18th International Ship and Offshore Structures Congress, Vol.1 (2012), Rostock.

\section{CONTACT WITH AUTHOR}

$$
\begin{gathered}
\text { Department of Naval Architecture } \\
\text { and Marine Engineering } \\
\text { Karadeniz Technical University } \\
61530 \text { Camburnu/Trabzon } \\
\text { Turkey }
\end{gathered}
$$

Phone: +90 462752 2805-8058 Fax: +904627522158 e-mail: hasanolmez@ktu.edu.tr 